\title{
Using past growth to improve individual-tree diameter growth models for uneven-aged mixtures of Pinus sylvestris L. and Pinus nigra Arn. in Catalonia, north-east Spain
}

\author{
Antoni Trasobares ${ }^{\mathrm{a} *}$, Timo PUKKalA ${ }^{\mathrm{b}}$ \\ ${ }^{a}$ Centre Tecnològic Forestal de Catalunya, Pujada del seminari s/n, 25280, Solsona, Spain \\ ${ }^{b}$ Faculty of Forestry, University of Joensuu, PO Box 111, 80101 Joensuu, Finland
}

(Received 18 February 2003; accepted 20 August 2003)

\begin{abstract}
In this study, growth models of individual tree diameter for uneven-aged mixtures of $P$. sylvestris and $P$. nigra in Catalonia were developed using a past growth index as site descriptor. These models were compared to an earlier model, based on the same data, that did not use past growth as a predictor. The growth index was calculated as a ratio of the measured and predicted past growth of sample trees within a given stand, the predictors pertaining to an average site. The models for future growth were based on 7982 and 5673 observations, and the models for past growth on 1997 and 1686 observations for P. sylvestris and P. nigra, respectively. Due to the applied Snowdon correction, the biases for the diameter growth models were zero. The relative RMSE values were $56.3 \%$ for the earlier $P$. sylvestris model and $52.0 \%$ for the new model, and $48.7 \%$ for the earlier P. nigra model and $47.1 \%$ for the new model. The accuracy of stand-level predictions (10-year change in basal area of living pines in the inventory plots) was better for the new models (Bias $\%=2.79$ and RMSE $\%=34.79$ ) than for the earlier ones (Bias $\%=3.27$ and RMSE $\%=41.54$ ). The results indicate that the new models adapt to specific stand conditions better than models that omit past growth measurements.
\end{abstract}

growth index / mixed models / mixed stand / Scots pine / black pine

Résumé - Utilisation de la croissance passée pour l'évaluation du site dans des modèles non spatialisés de croissance en diamètre pour des peuplements irréguliers et mélangés de Pinus sylvestris L. et Pinus nigra Arn. en Catalogne (Nord-Est de l'Espagne). Dans cette étude, des modèles de croissance en diamètre pour des peuplements irréguliers et mélangés de Pinus sylvestris L. et Pinus nigra Arn. en Catalogne ont été développés en utilisant un indice de croissance passée comme prédicteur du site. Ces modèles étaient comparés avec un modèle antérieur, à partir des mêmes valeurs, qui n'utilisait pas la croissance passée comme prédicteur. L'indice de croissance a été calculé comme un rapport de la croissance passée mesurée et la croissance passée prédite des arbres échantillonnées dans une placette donnée, avec des prédicteurs concernant un site moyen. Les modèles pour la croissance future correspondent à 7982 et 5673 observations, et les modèles pour la croissance passée à 1997 et 1686 observations pour $P$. sylvestris et $P$. nigra, respectivement. Les biais pour les modèles de croissance en diamètre sont zéro en raison de l'application de la correction de Snowdon. Les valeurs relatives du RMSE étaient $56.3 \%$ pour le modèle antérieur de $P$. sylvestris et $52.0 \%$ pour le nouveau modèle, et $48.7 \%$ pour le modèle antérieur de $P$. nigra et $47.1 \%$ pour le nouveau modèle. La précision des prédictions au niveau des placettes (dérive en surface terrière pour 10-années des arbres vivants dans les placettes d'inventaire) était meilleure pour les nouveaux modèles (Biais $\%=2.79$ et RMSE $\%=34.79$ ) que pour les modèles antérieures (Biais $\%=3.27$ et RMSE $\%=$ 41.54). Les résultats indiquent que les nouveaux modèles s'adaptent mieux aux conditions spécifiques de peuplement que les modèles omettant les mesures de croissance passée.

indice de croissance / modèles mixtes / peuplement mélangé / pin sylvestre / pin laricio

\section{INTRODUCTION}

Some variables, such as dominant height, stand age and site index, used in growth models for even-aged stands [13] are not directly applicable to uneven-aged stands [22]. The ages of individual trees of an uneven-aged stand are often unknown, which means that neither stand nor tree age is a useful predictor in a model. An alternative to the use of age and dominant height is to obtain site information from topographic descriptors such as elevation, slope, aspect, location descriptors (e.g., latitude) and soil type $[11,22]$. These variables may be applied to both uneven-aged and even-aged stands. Another possibility is to rely on the presence of plant species that indicate site fertility [19]. However, this type of data is not always available and species occurrence is affected, for instance, by management, forest fires and grazing.

\footnotetext{
* Corresponding author: antoni.trasobares@ctfc.es
} 
Trasobares et al. [19] used topographic and location variables in individual-tree diameter growth models for uneven-aged mixtures of $P$. sylvestris and $P$. nigra in Catalonia (north-east Spain). These models provided correct average predictions, but the site descriptors used accounted for only a small part of the variation in growth among stands. The low degree of explained variation may have resulted from variation in variables that were not included in the models [1,3] such as soil type and soil depth. Therefore, other information available in forest inventory data, such as past growth measurements from sample trees, should be analysed and tested as potential site descriptors.

Tree growth is often modelled using tree size, competition and site variables as predictors [11,22]. If a sample is collected so that all site levels are evenly represented in different treesize (dbh) and competition (basal area, basal area of trees larger than the subject tree) classes, and there are no genetic differences at the stand-level (planting of improved seedlings) a simple model predicting tree growth on an average site can be developed using tree size and competition variables as predictors but omitting site [20]. An index for site description can then be obtained by rating the measured growth of sample trees to their predicted growth. Because tree size and competition variables often correlate with site, it is better to call the site descriptor growth index rather than site index. This kind of growth index can be measured rather easily. In forest inventories in Catalonia, past growth from a few sample trees per stand is often available, which allows practical application.

In this study, models of the growth of individual-tree diameter for uneven-aged mixtures of $P$. sylvestris and $P$. nigra in Catalonia were developed using a past growth index as an additional predictor. Separate models were developed for $P$. sylvestris and $P$. nigra. The growth index was calculated as the ratio of the measured and the predicted past growth of sample trees within a given stand, the predicted past growth being calculated for an average site level. The models developed were compared to those of Trasobares et al. [19], which did not use past growth as a predictor, although the two model versions were based on the same data set.

\section{MATERIALS AND METHODS}

\subsection{Data}

The data were provided by the Spanish National Forest Inventory [2,5-8], which consists of a systematic sample of permanent plots distributed on a square grid of $1 \mathrm{~km}$, with a remeasurement interval of 10 -years. From inventory plots over the whole of Catalonia, 922 plots were selected that represented all degrees of mixture (including pure stands) between $P$. sylvestris and $P$. nigra. The criterion for plot selection was that the occupation of one (pure stands) or two (mixed stands) of the studied species in the stands should be at least $90 \%$. Most of the stands were naturally regenerated. The sample plots were established in 1989 and 1990. The plots were remeasured in 2000 and 2001. A hidden plot design was used: plot centres were marked by an iron stake buried underground, which was relocated with a metal detector. During the measurements, trees were recorded according to their polar coordinates and were marked only temporarily. The sampling method used circular plots in which the plot radius depended on the diameter of the tree at breast height (dbh, $1.3 \mathrm{~m})$ (Tab. I).

At the time of plot establishment, the radial increment of the last 5 years was measured in the field (averaging two perpendicular measures,
Table I. Plot radius for different classes of tree dbh.

\begin{tabular}{lc}
\hline $\mathrm{dbh}$ & Plot radius, $\mathrm{m}$ \\
\hline $75 \leq \mathrm{dbh}<125 \mathrm{~mm}$ & 5 \\
$125 \leq \mathrm{dbh}<225 \mathrm{~mm}$ & 10 \\
$225 \leq \mathrm{dbh}<425 \mathrm{~mm}$ & 15 \\
$\mathrm{dbh} \geq 425 \mathrm{~mm}$ & 25 \\
\hline
\end{tabular}

and in most cases using a lens) from up to six randomly selected trees. At each measurement, the following data were recorded for every sample tree: species, dbh, total height, and distance and azimuth from the plot centre. In the second measurement, a tree already measured in the first measurement was identified as: standing, dead or thinned. The standing trees resulted in 7982 diameter growth observations for P. sylvestris (Tab. II) and 5673 diameter growth observations for $P$. nigra (Tab. III). The past 5-year radial increment was measured from 1998 P. sylvestris (Tab. II) and 1687 P. nigra (Tab. III) trees. At each time of measurement the characteristics of the growing stock were computed from the individual-tree measurements of the plots.

\subsection{Developing a growth index for site evaluation}

To predict the past radial growth of a tree growing on an average site, simple linear models were developed. The predictors were chosen from tree size and competition, as well as their transformations. All predictors had to be significant at the 0.05 level, and the residuals had to indicate a non-biased model. The linear models were estimated using the ordinary least squares (OLS) technique in SPSS [16]. The models for the past radial increment of $P$. sylvestris and $P$. nigra were as follows:

$$
\begin{aligned}
\operatorname{pir} 5= & \beta_{0}+\beta_{1} \times \frac{1}{d b h}+\beta_{2} \times \ln (d b h) \\
& +\beta_{3} \times \ln \left(\left(\frac{B A L}{\ln (d b h+1)}\right)+1\right)+\beta_{4} \times \ln (G)+e
\end{aligned}
$$

where pir5 is past radial increment without bark ( $\mathrm{mm}$ in 5 years), $d b h$ is diameter at breast height $(\mathrm{cm}), B A L$ is the total basal area of trees larger than the subject tree $\left(\mathrm{m}^{2} \cdot \mathrm{ha}^{-1}\right)$, and $G$ is stand basal area $\left(\mathrm{m}^{2} \cdot \mathrm{ha}^{-1}\right)$.

Once past radial growth of an individual-tree was predicted, the ratio of the measured and the predicted past radial growth was calculated for all trees for which past growth was measured. The final growth index of a species in a plot (Eq. (2)) was calculated by averaging the past growth ratio of the trees of the same species within the plot:

$$
G I=\frac{1}{n} \sum_{i=1}^{n}\left(\operatorname{pir} 5_{i} \underset{\operatorname{pir}_{i}}{\wedge}\right)
$$

where $G I$ is the stand growth index, pid $5_{i}$ is measured past underbark radial growth ( $\mathrm{mm}$ in 5 years) of tree $i$ in the plot, $p i \hat{d} 5_{i}$ is predicted past radial growth ( $\mathrm{mm}$ in 5 years) of tree $i$ in the plot. Growth index values larger than one indicate a better-than-average growth, values close to one average growth, and values smaller than one, poor growth.

\subsection{Diameter increment modelling}

The predicted variable in the diameter growth models was the logarithmic transformation of 10-year diameter growth. The predictors were chosen from tree size, competition and site variables, as well as their transformations. Due to the hierarchical structure of the data (trees are grouped into plots, and plots are grouped into provinces), 
Table II. Mean, standard deviation (S.D.) and range of the main characteristics in the study material related to P. sylvestris.

\begin{tabular}{|c|c|c|c|c|c|}
\hline Variable $^{\mathrm{a}}$ & $\mathrm{N}$ & Mean & S.D. & Minimum & Maximum \\
\hline \multicolumn{6}{|c|}{ Past radial growth model (Eq. (1)) } \\
\hline $\operatorname{pir} 5(\mathrm{~mm} / 5 \mathrm{a})$ & 1998 & 8.2 & 3.9 & 1 & 28 \\
\hline$d b h(\mathrm{~cm})$ & 1998 & 21.5 & 8.4 & 7.8 & 76.1 \\
\hline$B A L\left(\mathrm{~m}^{2} \cdot \mathrm{ha}^{-1}\right)$ & 1998 & 8.4 & 7.8 & 0 & 50.4 \\
\hline$G\left(\mathrm{~m}^{2} \cdot \mathrm{ha}^{-1}\right)$ & 1998 & 17.7 & 10.1 & 1.3 & 55.1 \\
\hline \multicolumn{6}{|c|}{ Diameter growth models (Eq. (3)) } \\
\hline $\operatorname{id10}(\mathrm{cm} / 10 \mathrm{a})$ & 7982 & 2.6 & 1.6 & 0.1 & 12.4 \\
\hline$d b h(\mathrm{~cm})$ & 7982 & 20.8 & 8.4 & 5.4 & 76.1 \\
\hline BALsyl $\left(\mathrm{m}^{2} \mathrm{ha}^{-1}\right)$ & 7982 & 10.2 & 8.9 & 0 & 50 \\
\hline BALnig $+\operatorname{acc}\left(\mathrm{m}^{2} \cdot \mathrm{ha}^{-1}\right)$ & 7982 & 1.7 & 3.3 & 0 & 38.9 \\
\hline BALthin $\left(\mathrm{m}^{2} \cdot \mathrm{ha}^{-1}\right)$ & 7982 & 0.9 & 2.8 & 0 & 34.7 \\
\hline$G\left(\mathrm{~m}^{2} \cdot \mathrm{ha}^{-1}\right)$ & 629 & 23.2 & 11.2 & 1.3 & 55.1 \\
\hline GI & 629 & 1.01 & 0.41 & 0.25 & 2.81 \\
\hline \multicolumn{6}{|c|}{ Random plot factor models (Eq. (5)), } \\
\hline$u_{l k}(\ln (\mathrm{cm} / 10 \mathrm{a}))$ & 629 & 0 & 0.23 & -1.04 & 0.71 \\
\hline$E L E(100 \mathrm{~m})$ & 629 & 9.9 & 3.4 & 2 & 19 \\
\hline SLO (\%) & 629 & 35.9 & 9.3 & 7.5 & 41.6 \\
\hline
\end{tabular}

a $N$ : number of observations at tree- and stand-level; pir5: 5-year past radial increment; $d b h$ : diameter at breast height; $B A L$ : competition index calculated from all species; $G$ : stand basal area; id10: 10-year diameter increment; BALsyl: competition index of P. sylvestris; BALnig + acc: competition index of P. nigra and accompanying species; BALthin: 10-year thinned competition; GI: stand growth index; $u_{l k}$ : random between-plot factor; ELE: elevation; $S L O$ : slope.

Table III. Mean, standard deviation (S.D.) and range of the main characteristics in the study material related to P. nigra.

\begin{tabular}{|c|c|c|c|c|c|}
\hline Variable $^{\mathrm{a}}$ & $\mathrm{N}$ & Mean & S.D. & Minimum & Maximum \\
\hline \multicolumn{6}{|c|}{ Past radial growth model (Eq. (1)) } \\
\hline $\operatorname{pir} 5(\mathrm{~mm} / 5 \mathrm{a})$ & 1687 & 7.7 & 3.3 & 1 & 28 \\
\hline$d b h(\mathrm{~cm})$ & 1687 & 20.6 & 7.6 & 7.6 & 73.8 \\
\hline$B A L\left(\mathrm{~m}^{2} \cdot \mathrm{ha}^{-1}\right)$ & 1687 & 6.6 & 6.5 & 0 & 53.4 \\
\hline$G\left(\mathrm{~m}^{2} \cdot \mathrm{ha}^{-1}\right)$ & 1687 & 16.2 & 9.1 & 1.3 & 59.4 \\
\hline \multicolumn{6}{|c|}{ Diameter growth models (Eq. (4)) } \\
\hline$i d 10(\mathrm{~cm} / 10 \mathrm{a})$ & 5673 & 2.8 & 1.5 & 0.1 & 12.8 \\
\hline$d b h(\mathrm{~cm})$ & 5673 & 18.9 & 8.1 & 7.5 & 73.8 \\
\hline BALnig $\left(\mathrm{m}^{2} \cdot \mathrm{ha}^{-1}\right)$ & 5673 & 8.3 & 7.6 & 0 & 53.9 \\
\hline$B A L s y l+\operatorname{acc}\left(\mathrm{m}^{2} \cdot \mathrm{ha}^{-1}\right)$ & 5673 & 2.1 & 3.8 & 0 & 44.7 \\
\hline BALthin $\left(\mathrm{m}^{2} \cdot \mathrm{ha}^{-1}\right)$ & 5673 & 1.4 & 3.2 & 0 & 38.2 \\
\hline GI & 517 & 0.97 & 0.34 & 0.28 & 2.44 \\
\hline \multicolumn{6}{|c|}{ Random plot factor models (Eq. (6)) } \\
\hline$u_{l k}(\ln (\mathrm{cm} / 10 \mathrm{a}))$ & 517 & 0 & 0.24 & -0.95 & 0.64 \\
\hline ELE $(100 \mathrm{~m})$ & 517 & 8.1 & 2.7 & 2 & 15 \\
\hline $\operatorname{SLO}(\%)$ & 517 & 35.1 & 10.2 & 1.5 & 41.6 \\
\hline $\operatorname{LAT}(100 \mathrm{~km})$ & 517 & 46.42 & 0.45 & 45.10 & 47.07 \\
\hline $\operatorname{CON}(\mathrm{km})$ & 517 & 80.7 & 29.2 & 15.3 & 146.2 \\
\hline
\end{tabular}

${ }^{a} N$ : number of observations at tree- and stand-level; pir5: 5-year past radial increment; $d b h$ : diameter at breast height; $B A L$ : competition index calculated from all species; $G$ : stand basal area; id10: 10-year diameter increment; BALnig: competition index of P. nigra; BALsyl + acc: competition index of P. sylvestris and accompanying species; BALthin: 10-year thinned competition; GI: stand growth index; $u_{l k}$ : random between-plot factor; ELE: elevation; $S L O$ : slope; $L A T$ : latitude; $C O N$ : continentality.

the generalised least-squares (GLS) technique was applied to fit the mixed linear models. The residual variation was therefore divided into between-province, between-plot and between-tree components. The linear models were estimated using the maximum likelihood procedure of the computer software PROC MIXED in SAS/STAT [14]. The models were exactly the same as those of Trasobares et al. [19], but the past growth index was used as an additional predictor. The $P$. sylvestris (Eq. (3)) and P. nigra (Eq. (4)) diameter growth models were as follows:

$$
\begin{aligned}
\ln \left(i d 10_{l k t}\right) & =\beta_{0}+\beta_{1} \times \frac{1}{d b h_{l k t}}+\beta_{2} \times \ln \left(d b h_{l k t}\right)+\beta_{3} \times \frac{B A L s y l_{l k}}{\ln \left(d b h_{l k t}+1\right)} \\
& +\beta_{4} \times \frac{B A L n i g+a c c_{l k}}{\ln \left(d b h_{l k t}+1\right)}+\beta_{5} \times \frac{\text { BALthin }_{l k}}{\ln \left(d b h_{l k t}+1\right)}+\beta_{6} \times \ln \left(G_{l k}\right) \\
& +\beta_{7} \times \ln \left(G I_{l k}\right)+u_{l}+u_{l k}+e_{l k t}
\end{aligned}
$$




$$
\begin{aligned}
& \ln \left(i d 10_{l k t}\right)=\beta_{0}+\beta_{1} \times \frac{1}{d b h_{l k t}}+\beta_{2} \times \ln \left(d b h_{l k t}\right)+\beta_{3} \times \frac{B A \operatorname{Lnig}_{l k}}{\ln \left(d b h_{l k t}+1\right)} \\
& +\beta_{4} \times \frac{B A L s y l+a c c_{l k}}{\ln \left(d b h_{l k t}+1\right)}+\beta_{5} \times \frac{B A \operatorname{Lthin}_{l k}}{\ln \left(d b h_{l k t}+1\right)}+\beta_{6} \times \ln \left(G I_{l k}\right)+u_{l}+u_{l k}+e_{l k t}
\end{aligned}
$$

where $i d 10$ is future diameter growth ( $\mathrm{cm}$ in 10 years), $d b h$ is diameter at breast height $(\mathrm{cm}), B A L s y l$ is the total basal area of $P$. sylvestris trees larger than the subject tree $\left(\mathrm{m}^{2} \cdot \mathrm{ha}^{-1}\right), B A L n i g+a c c$ is the total basal area of trees that are not $P$. sylvestris and are larger than the subject tree $\left(\mathrm{m}^{2} \cdot \mathrm{ha}^{-1}\right)$, BALnig is the total basal area of $P$. nigra trees larger than the subject tree $\left(\mathrm{m}^{2} \cdot \mathrm{ha}^{-1}\right), B A L s y l+a c c$ is the total basal area of trees other than P. nigra and larger than the subject tree $\left(\mathrm{m}^{2} \cdot \mathrm{ha}^{-1}\right)$, BALthin is the total basal area of trees larger than the subject tree and thinned during the next 10 -year period $\left(\mathrm{m}^{2} \cdot \mathrm{ha}^{-1}\right), G$ is stand basal area $\left(\mathrm{m}^{2} \cdot \mathrm{ha}^{-1}\right)$, and $G I$ is the stand growth index. Subscripts $l, k$ and $t$ refer to province $l$, plot $k$, and tree $t$, respectively. $u_{l}, u_{l k}$ and $e_{l k t}$ are independent and identically distributed random between-province, betweenplot and between-tree factors with a mean of 0 and constant variances of $\sigma_{\text {prov, }}^{2} \sigma_{p l}^{2}$, and $\sigma_{t r}^{2}$, respectively.

In the earlier version of the diameter growth models [19] site effects were included by predicting the random plot factors $\left(u_{l k}\right)$ of the models from location and topographic descriptors (Eqs. (3) and (4)). In the new model versions, site effects were incorporated into the growth index $(G I)$ included in the fixed part of the models. However, the remaining between-plot variability still correlated logically with some of the previously used location descriptors. Thus, the random plot factor of the diameter growth models was predicted using the same variables (but only the significant ones) as in the plot factor models of Trasobares et al. [19]. The plot factor models for the diameter growth models of Trasobares et al. [19] for P. sylvestris (Eq. (5)) and P. nigra (Eq. (6)) were as follows:

$$
u_{l k}=\beta_{0}+\beta_{1} \times E L E_{l k}+\beta_{2} \times\left(E L E_{l k}\right)^{2}+\beta_{3} \times S L O_{l k}+e_{l k}
$$

$$
u_{l k}=\beta_{0}+\beta_{1} \times \ln \left(E L E_{l k}\right)+\beta_{2} \times S L O_{l k}+\beta_{3} \times C O N_{l k}+\beta_{4} \times L A T_{l k}+e_{l k}
$$

where $u_{l k}$ is the plot factor of equation 3 or $4, E L E$ is elevation (100 m), $S L O$ is slope (\%), CON is continentality (linear distance to the Mediterranean Sea, $\mathrm{km}$ ), and $L A T$ is latitude (y UTM coordinate, $100 \mathrm{~km}$ ). In simulations, the random plot factor $\left(u_{l k}\right.$ in Eqs. (3) or (4)) may be replaced by its prediction (Eq. (5) or (6)).

To convert the logarithmic predictions of equations 3 and 4 to the arithmetic scale, an empirical ratio estimator for bias correction in logarithmic regression was applied. As suggested by Snowdon [15], the proportional bias in logarithmic regression was estimated from the ratio of the mean diameter growth $i d 10$ and the mean of the backtransformed predicted values from the regression $\overline{\exp [\ln \hat{i d} 10]}$. The ratio estimator was therefore $\overline{i d 10} / \overline{\exp [\ln \hat{i d} 10]}$.

\subsection{Model evaluation}

The models were evaluated quantitatively by examining the magnitude and distribution of residuals for all possible combinations of variables included in the model. The aim was to detect any obvious dependencies or patterns that indicate systematic discrepancies. To determine the accuracy of model predictions, the bias and precision of the models were calculated $[4,10,21]$. The absolute and relative biases, and the root mean square error (RMSE) were calculated as follows:

$$
\begin{gathered}
\text { bias }=\frac{\sum\left(y_{i}-\hat{y}_{i}\right)}{n} \\
\text { bias } \%=100 \times \frac{\sum\left(y_{i}-\hat{y}_{i}\right) / n}{\sum \hat{y}_{i} / n} \\
R M S E=\sqrt{\frac{\sum\left(y_{i}-\hat{y}_{i}\right)^{2}}{n-1}} \\
R M S E \%=100 \times \frac{\sqrt{\sum\left(y_{i}-\hat{y}_{i}\right)^{2} /(n-1)}}{\sum \hat{y}_{i} / n}
\end{gathered}
$$

where $n$ is the number of observations, and $y_{i}$ and $\hat{y}_{i}$ are observed and predicted values, respectively. In the models the predicted value $\left(\hat{y}_{i}\right)$ was calculated using the model prediction of the plot factor.

In addition, the two model versions of the diameter growth models were further evaluated by graphic comparisons between measured and predicted tree and stand development. The predicted 10-year change in tree and stand basal area of the living pines (i.e., pines that were not thinned and did not die) in the inventory plots was compared to the measured change. To complement these graphics, the mean absolute residuals (tree level) were plotted against stand structure variables (e.g., basal area weighted mean dbh).

\section{RESULTS}

\subsection{Diameter growth models}

Parameter estimates of the past growth models (Eq. (1)) that were used to calculate growth indexes were logical and significant at the 0.05 level (Tabs. IV and V); the inverse transformation of dbh was not used in the model for P. nigra because it was clearly not significant. Parameter estimates of the models for future diameter growth (Eqs. (3) and (4)) were also logical and significant at the 0.001 level. Parameter estimates of the plot factor models were significant at the 0.05 level.

The ratio estimators for the bias correction using both the fixed part and the predicted plot factors (Eqs. (3-6)) were 2.6374/ $2.2689=1.1624$ for $P$. sylvestris and $2.7937 / 2.6393=1.0585$ for P. nigra.

The bias of the models predicting past (Fig. 1) and future growth, when the fixed model part and the plot factor models were used, showed no trends when displayed as a function of predictors or predicted growth. Due to the ratio estimator used for correction of bias generated by the logarithmic transformation of the dependent variable, the absolute and relative biases for the new $P$. sylvestris and $P$. nigra diameter growth models were zero.

\subsection{Comparison to the earlier models}

The past growth index $(G I)$ had a positive effect on diameter growth (Eqs. (3) and (4)) and was highly significant. When the growth index was used as an additional predictor in the fixed part of the models, the between-plot residual variance $\left(\sigma_{p l}^{2}\right)$ was 
Table IV. Estimates of the parameters and variance components of the $P$. sylvestris past radial growth model (Eq. (1)), diameter growth models (Eq. (3)) and the corresponding plot factor models (Eq. (5)) ${ }^{\mathrm{a}}$.

\begin{tabular}{|c|c|c|c|c|c|}
\hline Parameter & $\begin{array}{l}\text { Past radial growth model } \\
\text { (Eq. (1)) }\end{array}$ & $\begin{array}{l}\text { New diameter growth } \\
\text { model (Eq. (3)) }\end{array}$ & $\begin{array}{l}\text { New plot factor model } \\
\text { (Eq. (5)) }\end{array}$ & $\begin{array}{l}\text { Initial diameter growth } \\
\text { model (Eq. (3)) }\end{array}$ & $\begin{array}{l}\text { Initial plot factor model } \\
\text { (Eq. (5)) }\end{array}$ \\
\hline \multirow[t]{2}{*}{$\beta_{0}$} & 28.3833 & 5.4684 & 0.1631 & 5.5117 & 0.5180 \\
\hline & $(4.8867)$ & $(0.3267)$ & $(0.0750)$ & $(0.3304)$ & $(0.1065)$ \\
\hline \multirow[t]{2}{*}{$\beta_{1}$} & -64.2310 & -15.1155 & -0.0403 & -15.1681 & -0.0936 \\
\hline & $(24.9798)$ & $(1.3579)$ & $(0.0150)$ & $(1.3670)$ & $(0.0198)$ \\
\hline \multirow[t]{2}{*}{$\beta_{2}$} & -4.4382 & -1.0207 & 0.0022 & -1.0376 & 0.0048 \\
\hline & (1.2044) & $(0.0859)$ & $(0.0010)$ & $(0.0877)$ & $(0.0009)$ \\
\hline \multirow[t]{2}{*}{$\beta_{3}$} & -1.1610 & -0.0646 & - & -0.0649 & -0.0033 \\
\hline & $(0.2098)$ & $(0.0043)$ & & $(0.0045)$ & $(0.0013)$ \\
\hline \multirow[t]{2}{*}{$\beta_{4}$} & -0.7951 & -0.1014 & - & -0.1081 & - \\
\hline & $(0.1942)$ & $(0.0098)$ & & $(0.0102)$ & \\
\hline \multirow[t]{2}{*}{$\beta_{5}$} & - & 0.0723 & - & 0.0749 & - \\
\hline & & $(0.0130)$ & & $(0.0144)$ & \\
\hline \multirow[t]{2}{*}{$\beta_{6}$} & - & -0.1832 & - & -0.2031 & - \\
\hline & & $(0.0287)$ & & $(0.0323)$ & \\
\hline$\beta_{7}$ & - & $\begin{array}{c}0.6434 \\
(0.0402)\end{array}$ & - & - & - \\
\hline$\sigma_{\mathrm{pl}}^{2}$ & - & 0.0882 & 0.0542 & 0.1449 & 0.0987 \\
\hline$\sigma_{t r}^{p 1}$ & 14.5761 & 0.3750 & - & 0.3747 & - \\
\hline RMSE & 3.8179 & 0.6805 & 0.2328 & 0.7208 & 0.3141 \\
\hline
\end{tabular}

${ }^{a}$ S.E. of estimates are given in parenthesis.

Table V. Estimates of the parameters and variance components of the P. nigra past radial growth model (Eq. (1)), diameter growth models (Eq. (4)) and the corresponding plot-factor models (Eq. (6)) $)^{\mathrm{a}}$.

\begin{tabular}{|c|c|c|c|c|c|}
\hline Parameter & $\begin{array}{l}\text { Past radial growth model } \\
\text { (Eq. (1)) }\end{array}$ & $\begin{array}{l}\text { New diameter growth } \\
\text { model (Eq. (3)) }\end{array}$ & $\begin{array}{l}\text { New plot factor model } \\
\text { (Eq. (5)) }\end{array}$ & $\begin{array}{l}\text { Initial diameter growth } \\
\text { model (Eq. (3)) }\end{array}$ & $\begin{array}{l}\text { Initial plot factor model } \\
\text { (Eq. (5)) }\end{array}$ \\
\hline$\beta_{0}$ & $\begin{array}{l}12.0829 \\
(0.8991)\end{array}$ & $\begin{array}{c}5.1081 \\
(0.3320)\end{array}$ & $\begin{array}{c}0.0413 \\
(0.0306)\end{array}$ & $\begin{array}{c}5.0363 \\
(0.3324)\end{array}$ & $\begin{array}{r}-16.3119 \\
(2.5990)\end{array}$ \\
\hline$\beta_{1}$ & - & $\begin{array}{c}-15.4850 \\
(1.3271)\end{array}$ & $\begin{array}{l}-0.0005 \\
(0.0003)\end{array}$ & $\begin{array}{r}-15.4677 \\
(1.3352)\end{array}$ & $\begin{array}{l}0.1602 \\
(0.0470)\end{array}$ \\
\hline$\beta_{2}$ & $\begin{array}{l}-0.6330 \\
(0.3048)\end{array}$ & $\begin{array}{l}-1.0053 \\
(0.0868)\end{array}$ & - & $\begin{array}{l}-1.0055 \\
(0.0881)\end{array}$ & $\begin{array}{l}-0.0036 \\
(0.0013)\end{array}$ \\
\hline$\beta_{3}$ & $\begin{array}{l}-1.3650 \\
(0.1796)\end{array}$ & $\begin{array}{l}-0.0932 \\
(0.0049)\end{array}$ & - & $\begin{array}{l}-0.0962 \\
(0.0051)\end{array}$ & $\begin{array}{l}-0.0061 \\
(0.0009)\end{array}$ \\
\hline$\beta_{4}$ & $\begin{array}{l}-0.4529 \\
(0.1648)\end{array}$ & $\begin{array}{l}-0.0752 \\
(0.0080)\end{array}$ & - & $\begin{array}{l}-0.0673 \\
(0.0083)\end{array}$ & $\begin{array}{l}0.3576 \\
(0.0561)\end{array}$ \\
\hline$\beta_{5}$ & - & $\begin{array}{c}0.0579 \\
(0.0132)\end{array}$ & - & $\begin{array}{c}0.0621 \\
(0.0143)\end{array}$ & - \\
\hline$\beta_{6}$ & - & $\begin{array}{c}0.5540 \\
(0.0440)\end{array}$ & - & - & - \\
\hline$\sigma_{\mathrm{pl}}^{2}$ & - & 0.0855 & 0.0567 & 0.1263 & 0.0840 \\
\hline$\sigma_{t r}^{2}$ & 10.1412 & 0.2663 & - & 0.2671 & - \\
\hline RMSE & 3.1845 & 0.5931 & 0.2382 & 0.6272 & 0.2898 \\
\hline
\end{tabular}

a S.E. of estimates are given in parenthesis.

significantly reduced as compared to the models of Trasobares et al. [19] (by 39.1\% for P. sylvestris and by 32.2\% for P. nigra). This means that a considerable part of the variation in growth among stands was explained by the calculated site descriptor.

The RMSE values were lower for the new models than for the earlier models of Trasobares et al. [19] (relative RMSE values in parenthesis): $1.48 \mathrm{~cm} / 10$ years $(56.3 \%)$ for the earlier P. sylvestris model and $1.37 \mathrm{~cm} / 10$ years $(52.0 \%)$ for the new model, $1.36 \mathrm{~cm} / 10$ years $(48.7 \%)$ for the earlier $P$. nigra model and $1.32 \mathrm{~cm} / 10$ years $(47.1 \%)$ for the new model.

The predicted and measured basal area growth of living pines in the inventory plots were plotted for the earlier and the new 


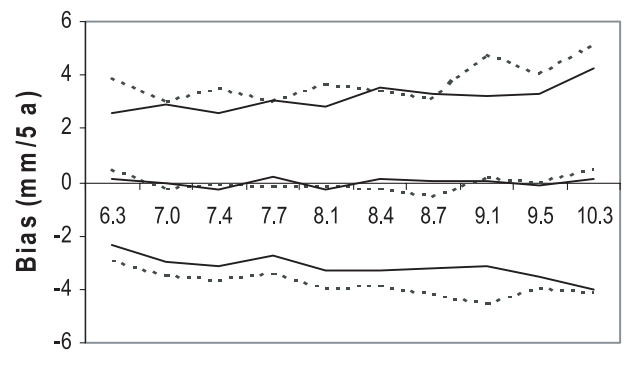

Predicted id $(\mathrm{mm} / 5$ a)

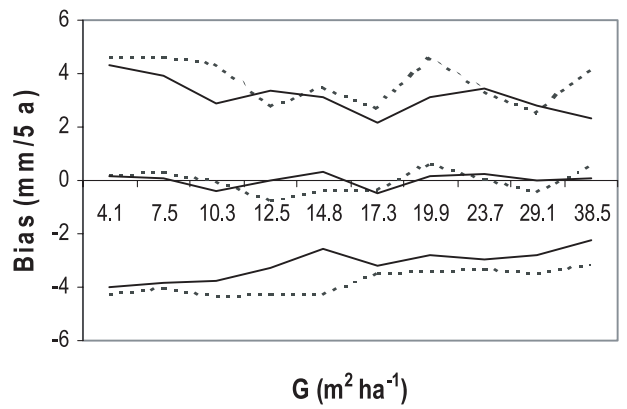

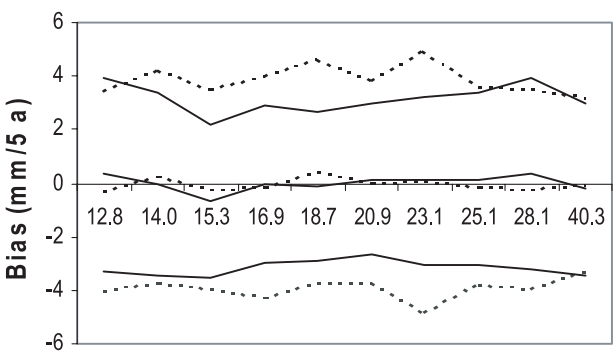

$\operatorname{Dbh}(\mathrm{cm})$

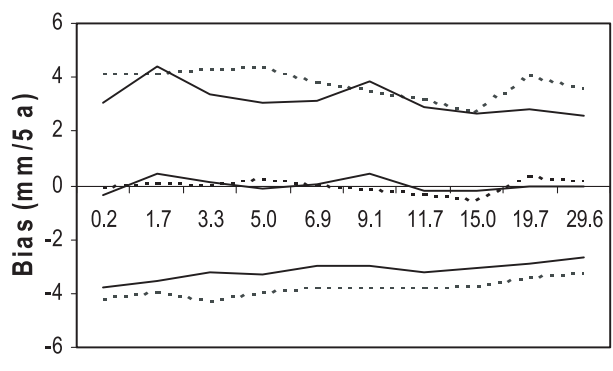

BAL $\left(m^{2} h a^{-1}\right)$

Figure 1. Estimated mean bias of the past radial growth model for $P$. sylvestris (dashed line) and $P$. nigra (solid line) as a function of predicted past radial growth, dbh, basal area, and total basal area of larger trees (thin lines indicate the standard error of the mean).

P. sylvestris (A)

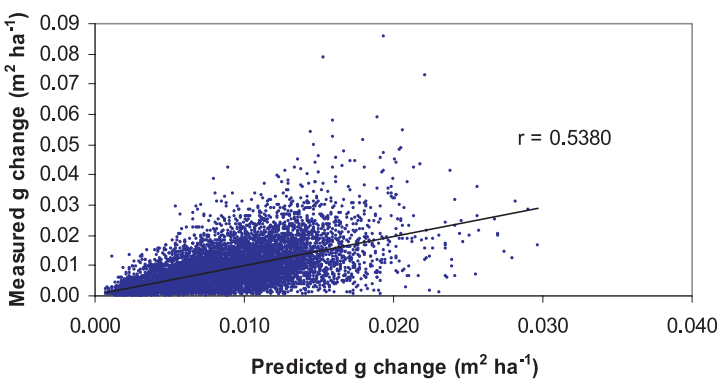

P. sylvestris (B)

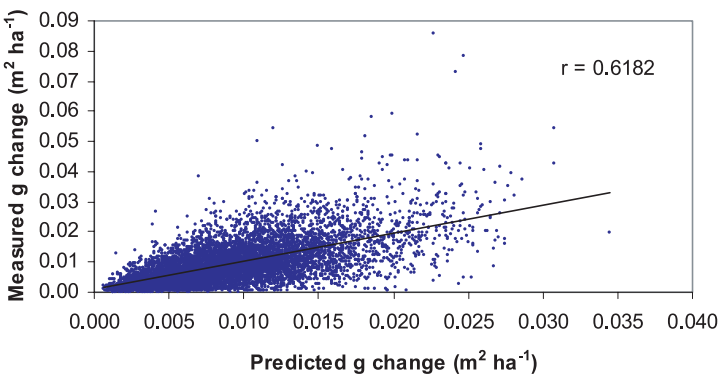

Figure 2. Measured and predicted 10-year changes in the tree basal area $(g)$ of living $P$. sylvestris in the inventory plots: using the initial version of the diameter growth models (A), using the new version of the diameter growth models (B). In each case, the fixed part of the models and the predicted plot factors were applied as well as the different correction factors for bias correction in diameter increment logarithmic regression.
P. nigra $(\mathrm{A})$

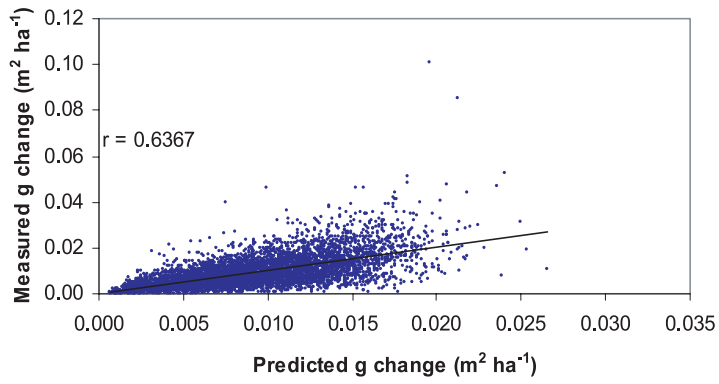

P. nigra (B)

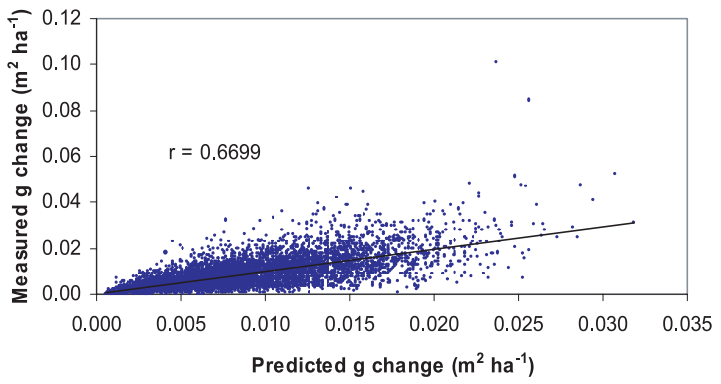

Figure 3. Measured and predicted 10-year changes in the tree basal area $(g)$ of living $P$. nigra in the inventory plots: using the initial version of the diameter growth models (A), using the new version of the diameter growth models (B). In each case, the fixed part of the models and the predicted plot factors were applied as well as the different correction factors for bias correction in diameter increment logarithmic regression. 
A

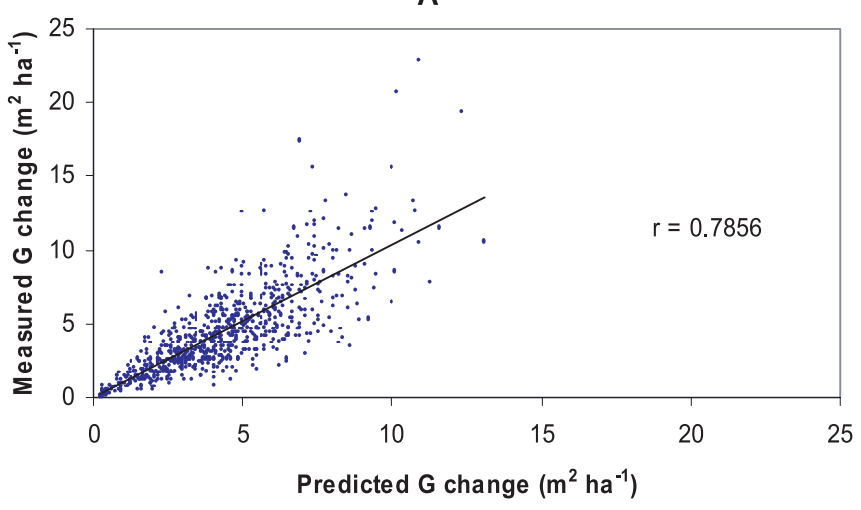

B

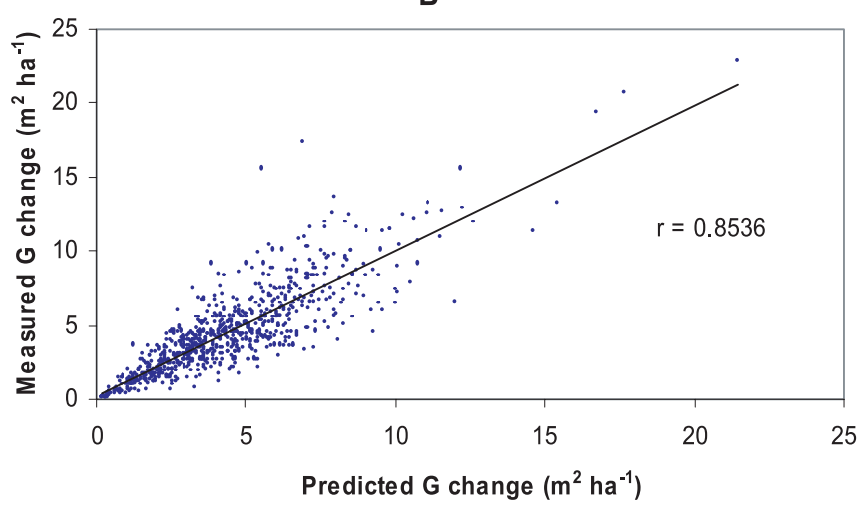

Figure 4. Measured and predicted 10-year changes in the stand basal area $(G)$ of the living pines in the inventory plots using the initial version of the diameter growth models (A), using the new version of the diameter growth models (B). In each case, the fixed part of the models and the predicted plot factors were applied as well as the different correction factors for bias correction in diameter increment logarithmic regression.

growth models (Figs. 2 and 3). The predicted plot factors have been added to the fixed part of the models, and the diameter-increment models have been corrected for logarithmic transformation. The graphs suggest that the accuracy of tree level predictions improved when the growth index was used as an additional predictor, this being clearer for $P$. sylvestris than for $P$. nigra. The bias for the earlier $P$. sylvestris model was $2.1 \%$ and for the new model 1.4\%; the RMSE for the earlier P. sylvestris model was $65.6 \%$ and for the new model $60.9 \%$; the bias for the earlier P. nigra model was $1.9 \%$ and for the new model $1.4 \%$; the RMSE for the earlier P. nigra model was 58.4 and for the new model $55.9 \%$.

The predicted stand basal-area growth for living pines in the inventory plots was compared to the measured growth (Fig. 4). The earlier models underpredicted the 10-year change in stand basal area of plots having exceptionally high growth (Bias = $0.1423 \mathrm{~m}^{2} \cdot \mathrm{ha}^{-1}$, Bias \% = 3.27; RMSE $=1.8069 \mathrm{~m}^{2} \cdot \mathrm{ha}^{-1}$; RMSE \% =41.54). A careful inspection of the plot data showed that the plots with the highest underprediction were young fastgrowing, rather even-aged stands [19]. When the new models were used, the predictions of stand development were more accurate $\left(\right.$ Bias $=0.1219 \mathrm{~m}^{2} \cdot \mathrm{ha}^{-1}$, Bias $\%=2.79, \mathrm{RMSE}=$
$1.5205 \mathrm{~m}^{2} \cdot \mathrm{ha}^{-1}$, RMSE $\%=34.79$ ), this being most evident for young, fast-growing stands. This aspect is also shown in Figure 5, where the mean absolute residuals of the $P$. sylvestris and $P$. nigra earlier and new model versions are plotted against the mean dbh weighted by basal area in each plot. The graphs show how the new models are more accurate, especially for $P$. sylvestris stands with small mean diameter.

\section{DISCUSSION}

This study presents new types of diameter growth models for uneven-aged mixtures of $P$. sylvestris and $P$. nigra in Catalonia compared to models developed by Trasobares et al. [19]. The new diameter growth models include a past growth index as an additional predictor for site evaluation. Both the earlier and the new models were developed using the same data, based on permanent sample plots measured twice at all sites of the Spanish National Forest Inventory in the region, which provides an outstanding database in terms of size (13 655 observations) and forest conditions. However, since the sampling method was not specifically designed to develop growth and yield models, the sample presented some limitations:

(1) The variable-radius circular plot sampling method used to collect the modelling data selected trees with unequal probability (Tab. I). However, despite its specific features, the variable radius circular plot is often the only feasible method for sampling irregular stand structures efficiently. This sampling method provides a good representation of large trees, which is usually a benefit from both inventory and modelling standpoints.

(2) It should also be remembered that sampling methods often are limited in their ability to represent spatial variability in stands [17]. Hence, the competition predictors used in the models might have sampling error associated with them, which will create bias when the models are used in simulations.

(3) Diameter growth is determined as the difference between two diameters. The breast height diameter may not have been measured at exactly the same height, and the direction of the diameter measurement may have differed on different measurement occasions. This results in greater errors in diameter increment than does measuring radial increment directly from increment borings. Nevertheless, assuming that the measurement errors were random, the large sample should compensate for this.

The growth index was based on the prediction of past growth of trees growing on an average site; the prediction models used tree size and competition descriptors as predictors, but omitted site. This approach was based on the assumption that all sitefertility levels were evenly represented in different classes of tree size and competition. In practice, however, this will hardly happen (e.g., high stand basal area may be more common in fertile sites). Therefore, when the effect of tree size and competition was removed from the measured past growth of a given tree - by dividing it by the predicted past growth on an "average" site part of the site effect was probably also removed. Hence, the calculated site descriptor was called growth index rather than site index. 
P. sylvestris (A)

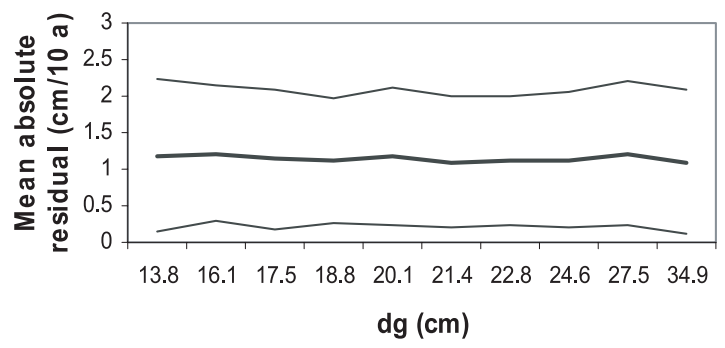

P. sylvestris (B)

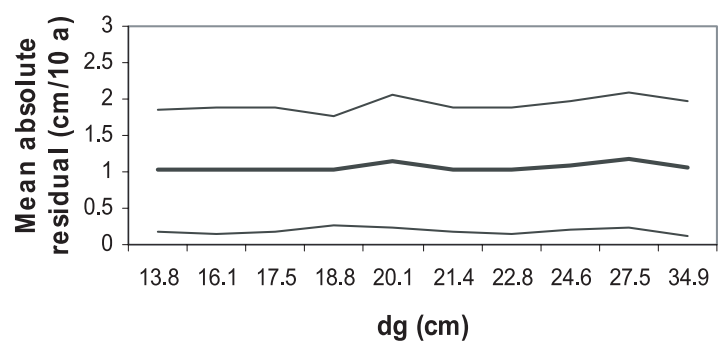

P. nigra (A)

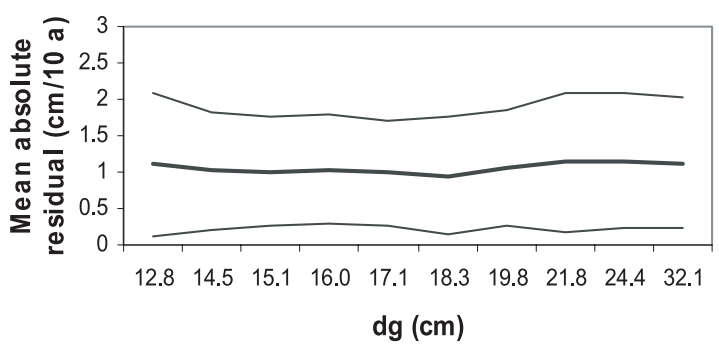

P. nigra (B)

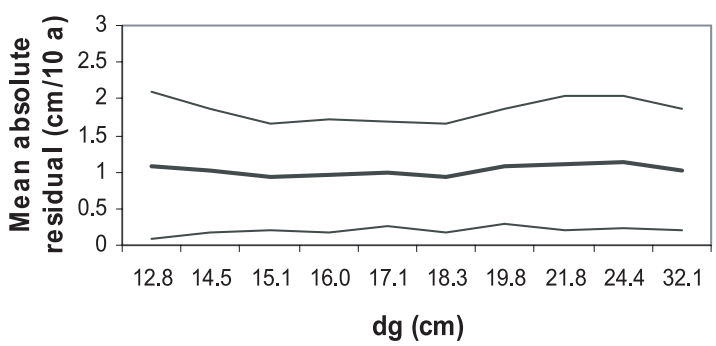

Figure 5. Mean absolute residuals of the $P$. sylvestris and $P$. nigra initial (A) and new (B) model versions as a function of the stand basal area weighted mean $\mathrm{dbh}(\mathrm{dg})$ in each plot. In each case, the fixed part of the models and the predicted plot factors were applied as well as the different correction factors for bias correction in diameter increment logarithmic regression.

The data used to calculate the past growth index were measured in the field (using a hand lens); laboratory measurements using a microscope would produce more accurate data, but they would be too costly for practical forest inventories. However, the rather large sample of past growth measurements (more than 1500 measurements for both species) partly compensates for lack of accuracy. Another limitation was that most sample trees for past growth measurement were medium sized; small and large trees were under-represented. Therefore, the inverse transformation of dbh (describing the ascending part of the positively skewed uni-modal shape typical of growth processes) was not a significant predictor in the past growth model of P. nigra.

In the modelling data, the average number of trees sampled for past growth measurement was three per plot, which agrees with the data often available from stand inventories in the region. As the growth index for every plot was calculated by averaging the past growth ratios (measured past growth divided by predicted past growth) of individual trees, the within-stand standard deviation of the growth ratio could be calculated. In the modelling data the mean within-stand standard deviation was 0.25 for $P$. sylvestris and 0.22 for $P$. nigra, the mean being equal to 1 for both species. For random sampling, the number of trees to be sampled for calculating the past growth ratio with a certain precision, can be obtained from [9]: $n=t_{\alpha}^{2} \times s^{2} / E^{2}$, where $n$ is the required sample size, $s$ is standard deviation of the considered characteristic, $E$ is the error which can be allowed, $\alpha$ is the probability of error greater than $E$, and $t$ is the related value from Student's distribution. If we use this formula and the standard deviation given above with a probability of error of 5\%, at least 5 trees should be selected for $P$. sylvestris to obtain an error smaller than 0.20 with $95 \%$ probability, 8 trees for an error of 0.15 , and 19 trees for an error of 0.10 ; for $P$. nigra at least 6 trees are required to keep the error under 0.20 with a probability of $95 \%, 11$ trees for an error of 0.15 , and 26 trees for an error of 0.10 . Because the sample is clustered (past growth sample trees were measured from plots), the number of required trees is probably somewhat higher.

Despite the mentioned limitations, for both pine species the calculated growth index was a strong predictor in the diameter growth models. The new models explained a greater part of the variation in growth (Figs. 2-5) than did the previous models based on the same data. The accuracy of the models was most clearly improved in young fast-growing and rather even-aged stands, for which the earlier model was rather inaccurate. The developed growth index accounted for both local and broad site effects. Nevertheless, the remaining between-plot variability still correlated logically with location variables such as stand elevation or continentality.

This study provides a method for defining a rather easily measurable growth index, which together with some location variables provides a way to evaluate site productivity in uneven-aged stands. The application potential of the growth index is broad. It can be applied with the data normally available from stand inventories in the region, and it applies to all age structures and degrees of mixture, including pure and even-aged stands. Models that include the growth index can also be used to optimize the stand management and to evaluate alternative management regimes for $P$. sylvestris and $P$. nigra stands in Catalonia $[12,18]$. 
Acknowledgements: Financial support for this study was provided by the Forest Technology Centre of Catalonia (Solsona, Spain). We are grateful to Jose Antonio Villanueva, head of the Spanish National Forest Inventory, for making the Forest Inventory data available and for his cooperation. We thank Editor G. Aussenac and the anonymous reviewers for their valuable comments. We thank Joann von Weissenberg for the linguistic revision of the manuscript.

\section{REFERENCES}

[1] Dennis B., Brown B.E., Stage A.R., Burkhart H.E., Clark S., Problems of modeling growth and yield of renewable resources, Am. Stat. 39 (1985) 374-383.

[2] DGCN, Tercer Inventario Forestal Nacional (1997-2006) Galicia: A Coruña, Ministerio de Medio Ambiente, Madrid, 2001.

[3] Fox J.C., Ades P.K., Bi H., Stochastic structure and individual-tree growth models, For. Ecol. Manage. 154 (2001) 261-276.

[4] Gadow K. von, Hui G., Modeling forest development, Faculty of Forest and Woodland Ecology, University of Göttingen, 1998.

[5] ICONA, Segundo Inventario Forestal Nacional (1986-1995) Cataluña: Barcelona, MAPA, Madrid, 1993.

[6] ICONA, Segundo Inventario Forestal Nacional (1986-1995) Cataluña: Girona, MAPA, Madrid, 1993.

[7] ICONA, Segundo Inventario Forestal Nacional (1986-1995) Cataluña: Lleida, MAPA, Madrid, 1993.

[8] ICONA, Segundo Inventario Forestal Nacional (1986-1995) Cataluña: Tarragona, MAPA, Madrid, 1993.

[9] Loetsch F., Haller K.E., Forest inventory: Statistics of forest inventory and information from aerial photographs, BLV Verlagsgesellschaft, München, 1973.

[10] Mabvurira D., Miina J., Individual-tree growth and mortality models for Eucalyptus grandis (Hill) Maiden plantations in Zimbabwe, For. Ecol. Manage. 161 (2002) 231-245.
[11] Monserud R.A., Sterba H., A basal area increment model for individual trees growing in even- and uneven-aged forest stands in Austria, For. Ecol. Manage. 80 (1996) 57-80.

[12] Palahí M., Pukkala T., Optimising the management of Scots pine (Pinus sylvestris L.) in north-east Spain, Ann. Sci. For. 60 (2003) 105-114.

[13] Palahí M., Pukkala T., Miina J., Montero G., Individual-tree growth and mortality models for Scots pine (Pinus sylvestris L.) in northeast Spain, Ann. Sci. For. 60 (2003) 1-10.

[14] SAS Institute Inc., SAS/STAT User's guide, version 8, Cary, NC: SAS Institute Inc., 1999, 3884 p.

[15] Snowdon P., A ratio estimator for bias correction in logarithmic regressions, Can. J. For. Res. 21 (1991) 720-724.

[16] SPSS Inc., SPSS Base system syntax reference Guide, Release 9.0, 1999.

[17] Stage A.R., Wykoff W.R., Adapting distance-independent forest growth models to represent spatial variability: effects of sampling design on model coefficients, For. Sci. 44 (1998) 224-238.

[18] Trasobares A., Pukkala T., Optimising the management of unevenaged Pinus sylvestris L. and Pinus nigra Arn. mixed stands in Catalonia, north-east Spain, Ann. For. Sci. 61 (2004), DOI: $10.1051 /$ forest:2004071.

[19] Trasobares A., Pukkala T., Miina J., Growth and yield model for uneven-aged mixtures of Pinus sylvestris L. and Pinus nigra Arn. in Catalonia, north-east Spain, Ann. For. Sci. 61 (2004) 9-24.

[20] Vanclay J.K., Site productivity assessment in rainforests: an objective approach using indicator species, in: Wan Razali W.M., Chan H.T., Appanah S. (Eds.), Proceedings of the Seminar on Growth and Yield in Tropical Mixed/Moist Forests, 20-24 June 1988, Kuala Lumpur, Forest Research Institute Malaysia, Kepong, pp. 225-241.

[21] Vanclay J.K., Modelling forest growth and yield: Applications to mixed tropical forests, CABI Publishing, Wallingford, UK, 1994.

[22] Wykoff R.W., A basal area increment model for individual conifers in the northern Rocky Mountains, For. Sci. 36 (1991) 1077-1104. 